\title{
Desempenho de Novilhos em Crescimento em Pastagem de Brachiaria decumbens Suplementados com Diferentes Fontes Energéticas no Período da Seca e Transição Seca-Águas ${ }^{1}$
}

\author{
Jocilaine Garcia ${ }^{2}$, Claudete Regina Alcalde ${ }^{3}$, Maximiliane Alavarse Zambom², Elias Nunes \\ Martins $^{3}$, Clóves Cabreira Jobim ${ }^{3}$, Sandra Regina Dias Ferreira Andrade ${ }^{4}$, Marcelo Farid Pereira ${ }^{5}$
}

\begin{abstract}
RESUMO - Objetivou-se, neste trabalho, estudar o efeito da suplementação, com diferentes fontes energéticas, sobre o desempenho de novilhos em crescimento e a viabilidade econômica da suplementação, bem como avaliar a disponibilidade e composição química da braquiária (Brachiaria decumbens Stapf), no período de julho a novembro, na região Oeste do Estado de São Paulo. Foram utilizados 42 novilhos da raça Nelore, distribuídos em três piquetes de 7,2 ha cada. As fontes energéticas utilizadas como suplementos foram: milho desintegrado com palha e sabugo (MDPS), farinha de mandioca de varredura (FMV) e casca do grão de soja (CGS). Todos os tratamentos continham farelo de algodão, para atingir $25 \%$ de PB, e foram fornecidos em nível de 1,3\% do PV. As pesagens dos animais foram realizadas a cada 14 dias e a disponibilidade de forragem foi estimada a cada 28 dias. A disponibilidade média de forragem foi de $2.570 \mathrm{~kg}$ de MS/ha e $1.306 \mathrm{~kg}$ de lâmina foliar/ha. A proporção de lâmina foliar apresentou comportamento quadrático em função do período experimental, com valor mínimo de 46,58\%, observado em agosto. Os teores médios de proteína bruta foram de: 4,45\% para planta inteira; 5,30\% para lâmina foliar e 2,83\% para o colmo + bainha. Os teores médios de FDN e FDA foram, respectivamente, de $70,61 \%$ e $39,93 \%$ para a planta inteira; $65,76 \%$ e 34,91\% para a lâmina foliar e 75,83\% e 47,90\% para o colmo + bainha. Entre os suplementos não houve diferença para ganho médio diário, apresentando média de $0,836 \mathrm{~kg} / \mathrm{animal} / \mathrm{dia}$. O suplemento mais viável economicamente foi o que continha a farinha de mandioca de varredura, pois, além de apresentar menor custo, foi o que proporcionou maior ganho animal, mostrando melhor relação receita: custo.
\end{abstract}

Palavras-chave: ganho de peso, oferta de forragem, resíduos agroindustriais, suplementação

\section{Development of Growing Steers on Brachiaria decumbens Supplemented with Different Energy Sources during the Dry Season and Transition from Dry to Wet Season}

\begin{abstract}
The aim of this work was evaluate the effect of supplementation with different energetic sources, on growing steers performance and economical viability, and also evaluate the structure and chemical composition of Signalgrass (Brachiaria decumbens) from July to November, on São Paulo state west region. Forty-two animals (Nelore) and three pastures of 7.2 ha each, were used. The energy sources used for supplements were: corn and cob with husks (CCH), cassava meal (CM) and soybean hulls (SH); each treatment had cottonseed meal to reach $25 \%$ of $\mathrm{CP}$, and was given at $1.30 \%$ of BW. The animal weight was verified at each 14 days and forage characteristics were evaluated at each 28 days. The average availability of forage was $2570 \mathrm{~kg}$ DM/ha and $1306 \mathrm{~kg}$ leaves/ha. Leaves proportion showed a quadratic behavior in function of experimental period, with minimum value of $46.58 \%$ observed in August. The average levels of CP were $4.45 \%$ for all plant, $5.30 \%$ for leaf e $2.83 \%$ for steam. The average levels of NDF and ADF were, respectively $70.61 \%$ and $39.93 \%$ for all plant, $65.76 \%$ and $34.91 \%$ for leaf, and $75.83 \%$ and $47.90 \%$ for steam. The supplements were not different on average daily gain, with average of $0.836 \mathrm{~kg} / \mathrm{animal} / \mathrm{day}$. The supplement more economically viable was the cassava meal, which showed lesser coasts and bigger animal gain with better relation income:costs.
\end{abstract}

Key Words: agricultural subproducts, forage availability, supplementation, weight gain

\section{Introdução}

No Brasil, a carne bovina é basicamente obtida por meio da produção a pasto. No entanto, sob condições de forrageiras tropicais mal manejadas, os bovinos dificilmente conseguem obter os nutrientes essenciais das forrageiras para um bom desempenho produtivo. As forrageiras tropicais, em geral, apresentam déficits nutricionais, que se agravam à medida que amadurecem, principalmente na estação seca (Andrade, 1995; EMBRAPA, 1995).

\footnotetext{
1 Parte da Dissertação apresentada pela primeira autora à Universidade Estadual de Maringá

2 Pós-Graduando do Programa de Pós-Graduação da Universidade Estadual de Maringá.

3 Professor - Departamento de Zootecnia - UEM, Bolsista do CNPq. Av. Colombo, 5790, CEP: 87020-900, Maringá - PR (cralcalde @wnet.com.br)

${ }^{4}$ Engenheira-Agrônoma.

5 Professor do Departamento de Economia - UEM.
} 
No período de seca, em muitas situações, o animal pode perder peso (Poppi \& McLennan, 1995; Euclides Filho et al., 1997) e apresentar o que é denominado de "efeito sanfona", ou seja, ocorrem altos ganhos de peso no período das águas e pouco ganho ou perda de peso no período da seca, ampliando, com isso, a idade de abate (Cardoso et al., 1998).

Para que os animais possam se desenvolver normalmente, buscando-se a antecipação da idade ao abate, surge a necessidade de eliminar as fases negativas do desenvolvimento com o suprimento de alimentos de acordo com as exigências dos animais (Euclides et al., 1997). A suplementação alimentar em pasto deve complementar o valor nutritivo da forragem disponível de forma a se atingir o ganho de peso desejado. Assim, é de fundamental importância conhecer a qualidade da forragem ofertada e as exigências nutricionais dos animais.

Geralmente, o ganho médio diário (GMD) de novilhos a pasto suplementados no primeiro inverno fica em torno de 0,400 a $0,700 \mathrm{~kg} / \mathrm{d}$, e a melhoria nos ganhos, no primeiro período seco, dos animais terá repercussão futura no desempenho desses animais (Peruchena, 1999).

Muitos trabalhos nos quais se avaliaram características de produção, principalmente para bovinos em crescimento, foram demonstradas melhorias resultantes da suplementação energética (Anderson et al., 1988; Vazant \& Cochran, 1994; Caton \& Dhuyvetter, 1997). Várias fontes energéticas chamadas de alternativas, em substituição aos alimentos convencionais, têm sido utilizadas na suplementação de ruminantes. A escolha dos subprodutos a ser utilizado depende da disponibilidade na região, qualidade e custo.

O milho é um dos grãos mais produzidos no Brasil, mas ao passar pelo processo de colheita mecanizada desprezam-se a palha e o sabugo, que podem ser utilizados na nutrição de ruminantes, reduzindo, portanto, os gastos com a mecanização (Paziani, 2000). O milho desintegrado com palha e sabugo (MDPS) é uma fonte de alta energia, sendo, ao mesmo tempo, rica em fibra, o que reduz os efeitos negativos dos carboidratos prontamente fermentáveis sobre a degradação da fibra.

Por outro lado, a casca do grão de soja é um subproduto do processamento industrial da soja e pode ser utilizado na alimentação animal como fonte energética de elevada degradação ruminal (Kung \& Lin, 1997). A fermentação no rúmen causada pelos microrganismos faz da casca do grão de soja uma fonte disponível de energia, sendo que a digestibilidade total é de mais de $70 \%$ para todos os nutrientes (Faulkner et al., 1994). Como um suplemento fibrosoenergético, pode melhorar a utilização de forragens de baixa qualidade, sem, no entanto, ocorrer efeitos associativos negativos (Martin \& Hibberd,1990; Kohlmeier, 1996).

Durante os processos de industrialização e transformação da mandioca em outros produtos, pode-se obter a farinha de mandioca de varredura (FMV), que é, a massa ralada, depositada no piso da indústria ao longo do dia de trabalho (Cereda, 1994). A FMV é uma fonte altamente energética, possuindo carboidratos de rápida fermentação no rúmen.

Objetivou-se, neste trabalho, estudar a utilização de diferentes fontes energéticas em suplementos sobre o desempenho de novilhos em crescimento e o custo da suplementação, bem como avaliar a disponibilidade e qualidade da Brachiaria decumbens, durante o período da seca e transição seca-águas.

\section{Material e Métodos}

O trabalho foi conduzido na Fazenda Colina, localizada em Álvares Machado, região oeste do Estado de São Paulo. O solo da região é do tipo litossolo arenoso e o clima é caracterizado por subtropical úmido mesotérmico (FCT-UNESP).

Os dados de precipitação pluviométrica mensal foram coletados na Casa da Lavoura de Álvares Machado, localizada a $10 \mathrm{~km}$ da propriedade (Figura 1).

Foram utilizados três piquetes de Brachiaria decumbens, divididos por cerca eletrificada, com área total de 21,6 ha, considerando a disposição de dois animais por hectare. Em cada piquete foi colocado cocho para suplementação (3,6 m lineares) e bebedouro.

No mês de janeiro de 2001, foram feitas amostragens do solo para correção e adubação. O solo apresentou a seguinte composição química: $\mathrm{pH}$ $\left(\mathrm{CaCl}_{2}\right)=4,6 ; \mathrm{pH}(\mathrm{SMP})=6,8 ; \mathrm{H}^{++} \mathrm{Al}^{+}=19,0^{*}$; $\mathrm{Al}^{+3}=1,0^{*} ; \mathrm{Ca}^{+2}=9,0^{*} ; \mathrm{Mg}^{+2}=2,0^{*} ; \mathrm{K}^{+}=0,5^{*}$; $\mathrm{P}=22 \mathrm{mg} / \mathrm{dm}^{3} ; \mathrm{SO}_{4}{ }^{-2} \mathrm{mg} / \mathrm{dm}^{3} ; \mathrm{MO}=10 \mathrm{~g} / \mathrm{dm}^{3}$ $\left({ }^{*} \mathrm{mmolc} / \mathrm{dm}^{3}\right)$. Foram aplicadas 1,25 tonelada de calcário/ha; 30 dias depois, adubou-se com $210 \mathrm{~kg}$ de super fosfato simples/ha e $100 \mathrm{~kg} / \mathrm{ha}$ de cloreto de potássio, seguindo-se uma adubação nitrogenada com $50 \mathrm{~kg} / \mathrm{ha}$ de uréia.

Foram utilizados 42 novilhos, da raça Nelore, nãocastrados, com idade de 10 meses e peso médio inicial 


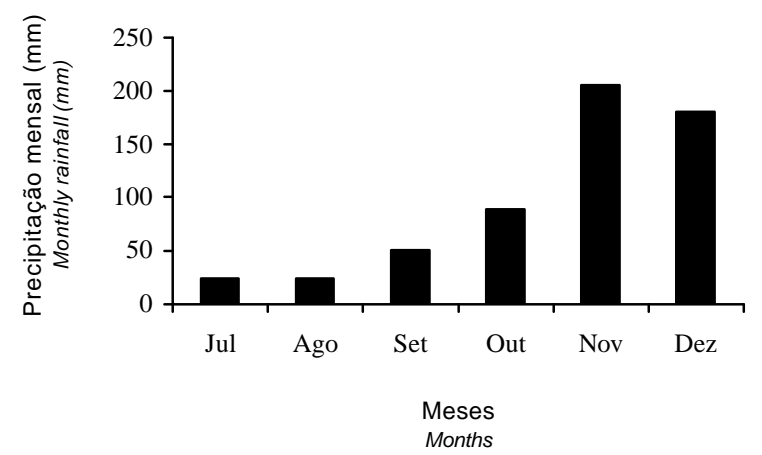

Figura 1 - Precipitação pluviométrica mensal durante o período experimental.

Figure 1 - Monthly precipitation during experimental period.

de $199 \mathrm{~kg}$. Antes de serem distribuídos nos tratamentos, os animais foram vacinados contra febre aftosa e receberam dose de vermífugo. Durante o experimento, foi realizada nova vacinação no dia $15 / 11 / 2001$, contra a febre aftosa, clostridiose e aplicado vermífugo à base de albendazol. O controle da mosca-do-chifre era realizado quando necessário.

Os animais foram identificados e distribuídos ao acaso em três tratamentos, variando-se a fonte de suplementação energética: milho desintegrado com palha e sabugo, farinha de mandioca de varredura e casca do grão de soja. O farelo de algodão foi utilizado como fonte protéica, para compor $25 \%$ de proteína bruta no suplemento. As composições percentuais dos alimentos nos suplementos, bem como as composições químicas dos suplementos são apresentadas na (Tabela 1).

Os suplementos foram ajustados de acordo com as recomendações feitas pelo NRC (1996), assumindo-se uma ingestão total de matéria seca diária de $2,6 \%$ do peso vivo. Considerando-se que a pastagem continha em torno de $4 \%$ de proteína bruta, para suprir diariamente as exigências diárias do animal em $400 \mathrm{~g}$ de proteína degradável e atender em torno de $78 \%$ de nutrientes digestíveis totais, os suplementos foram fornecidos a 1,3\% de matéria seca em relação ao peso vivo. Todos os animais receberam mistura mineral à vontade em cochos separados dos suplementos.

Os animais foram pesados no início do experimento e a cada 14 dias, no período entre 20/07/2001 a 23/11/2001. No mesmo dia de pesagem, realizou-se o rodízio seqüencial dos animais entre os piquetes.
Tabela 1 - Composição química e percentual dos ingredientes dos suplementos

Table 1 - Chemical and percentual composition of ingredients of the supplements

\begin{tabular}{|c|c|c|c|}
\hline \multirow[t]{2}{*}{$\begin{array}{l}\text { Alimentos } \\
\text { Feeds }\end{array}$} & \multicolumn{3}{|c|}{$\begin{array}{c}\text { Suplementos } \\
\text { Supplements }\end{array}$} \\
\hline & $\begin{array}{l}\text { SMDPS }^{1} \\
S C C H^{1}\end{array}$ & $\begin{array}{l}\mathrm{SFVM}^{2} \\
S C M^{2}\end{array}$ & $\begin{array}{c}\mathrm{SCGS}^{3} \\
S S H^{3}\end{array}$ \\
\hline $\begin{array}{l}\text { Milho desintegrado } \\
\text { com palha e sabugo } \\
\text { Corn and cob with husks }\end{array}$ & 50,13 & - & - \\
\hline $\begin{array}{l}\text { Farinha de mandioca } \\
\text { de varredura } \\
\text { Cassava meal }\end{array}$ & - & 46,33 & - \\
\hline $\begin{array}{l}\text { Casca do grão de soja } \\
\text { Soybean hulls }\end{array}$ & - & - & 58,67 \\
\hline $\begin{array}{l}\text { Farelo de algodão } \\
\text { Cottonseed meal }\end{array}$ & 49,87 & 53,67 & 41,33 \\
\hline $\begin{array}{l}\text { Composição química } \\
\text { Chemical composition }\end{array}$ & & & \\
\hline $\begin{array}{l}\operatorname{MS}(\%) \\
D M(\%)\end{array}$ & 92,54 & 92,65 & 92,87 \\
\hline $\begin{array}{l}\text { MO (\% MS }) \\
O M(\% \quad D M)\end{array}$ & 87,79 & 85,47 & 89,09 \\
\hline $\begin{array}{l}\mathrm{PB}(\% \mathrm{MS}) \\
C P(\% D M)\end{array}$ & 24,27 & 23,86 & 26,15 \\
\hline $\begin{array}{l}\mathrm{FDN}(\% \mathrm{MS}) \\
N D F(\% D M)\end{array}$ & 44,19 & 39,97 & 55,44 \\
\hline $\begin{array}{l}\mathrm{FDA}(\% \mathrm{MS}) \\
A D F(\% D M)\end{array}$ & 19,18 & 18,11 & 36,37 \\
\hline $\begin{array}{l}\mathrm{EE}(\% \mathrm{MS}) \\
E E(\% D M)\end{array}$ & 2,17 & 0,97 & 2,22 \\
\hline $\begin{array}{l}\mathrm{NDT}^{4}(\% \mathrm{MS}) \\
T D N\left(\begin{array}{ll}\% & D M\end{array}\right)\end{array}$ & 78,51 & 79,17 & 77,94 \\
\hline $\begin{array}{l}\mathrm{CHOT}^{5}(\% \mathrm{MS}) \\
\text { CHOT }(\% \mathrm{DM})\end{array}$ & 68,81 & 67,99 & 67,85 \\
\hline
\end{tabular}

${ }^{1}$ SMDPS: milho desintegrado com palha e sabugo + farelo de algodão; ${ }^{2}$ SFMV: farinha de mandioca de varredura + farelo de algodão; 3 SCGS: casca do grão de soja + farelo de algodão; 4\% NDT: obtido dos valores tabulados pelo NRC (1996); $5 \%$ CHOT: estimado pela equação: $100-(\%$ PB $+\%$ EE + \% Cinzas), proposta por Sniffen et al. (1992).

${ }^{1} \mathrm{SCCH}$ : corn and cob with husks + cottonseed meal; ${ }^{2}$ SCM: cassava meal + cottonseed meal: ${ }^{3}$ SSH: soybean hulls + cottonseed meal:4\% TDN: values tabulated by NRC (1996); $5 \%$ CHOT: estimated by equation: $100-(\% C P+$ $\% E E+\%$ Ash) proposed by Sniffen et al. (1992).

Todos os tratamentos passavam por todos os piquetes a cada 42 dias, visando, desse modo, eliminar possíveis efeitos da oferta de forragem. Portanto, para as avaliações de ganho de peso, foram considerados três períodos de 42 dias.

A avaliação da disponibilidade de forragem foi realizada a cada 28 dias, no período de 20/07/2001 a 12/11/2001, totalizando cinco medidas, utilizando-se o método de dupla amostragem (Wilm et al., 1944), 
usando a equação proposta por Gardner (1986). Foram colhidas 12 amostras de $0,25 \mathrm{~m}^{2}$ a cada 28 dias, conforme a técnica descrita por Holderbaun \& Sollenberg (1992). As amostras foram separadas em lâmina foliar e colmo + bainha, posteriormente secas em estufa a $55^{\circ} \mathrm{C}$, por 72 horas, e processadas em moinho do tipo faca com peneira com crivos de $1 \mathrm{~mm}$, para posteriores análises laboratoriais. Dessa forma, foi estimada a porcentagem de lâmina foliar e colmo + bainha em cada piquete e período.

Para avaliar a composição química da forragem, foram determinados os teores de matéria seca (MS), proteína bruta $(\mathrm{PB})$, matéria mineral $(\mathrm{MM})$, extrato etéreo (EE), fibra em detergente neutro (FDN) e fibra em detergente ácido (FDA), segundo os métodos descritos por Silva (1990).

Os nutrientes digestíveis totais (NDT) da forragem foram estimados pela equação proposta por Capelle et al. (2001):

$$
\mathrm{NDT}=83,79-0,4171 \mathrm{FDN}
$$

Os carboidratos totais (CHOT) foram obtidos por intermédio da equação proposta por Sniffen et al. (1992):

$$
\mathrm{CHOT}=100-(\% \mathrm{~PB}+\% \mathrm{EE}+\% \text { Cinzas })
$$

Para análise dos dados obtidos com relação à forragem, foram considerados cinco períodos experimentais, com intervalos de 28 dias, sendo utilizada a média dos quatro cortes por piquete. A análise estatística foi realizada utilizando-se o Sistema de Análises Estatísticas e Genéticas - SAEG (UFV, 1982), por meio de equações de regressão entre a variável independente (momento de amostragem) e as variáveis dependentes obtidas no experimento. Para o estabelecimento das equações, os meses foram codificados como 1, 2, 3, 4 e 5, respectivamente, para julho, agosto, setembro, outubro e novembro.

O delineamento experimental empregado para avaliação do desempenho animal foi o inteiramente casualizado, com três tratamentos e 14 repetições por tratamento. As análises estatísticas foram realizadas utilizando-se o Sistema de Análises Estatísticas e Genéticas - SAEG (UFV, 1982), segundo o modelo:

$$
\mathrm{Y}_{\mathrm{ijk}}=\mu+\mathrm{T}_{\mathrm{i}}+\mathrm{A}_{\mathrm{k}} / \mathrm{T}_{\mathrm{i}}+\mathrm{P}_{\mathrm{j}}+\mathrm{e}_{\mathrm{ijk}}
$$

em que $Y_{i j k}=$ observação individual do animal $\mathrm{k}$, do período $\mathrm{j}$, recebendo o tratamento $\mathrm{i} ; \mu=$ média geral;
$\mathrm{T}_{\mathrm{i}}=$ efeito do tratamento $\mathrm{i} ; \mathrm{i}=1 ; 2 ; 3 ; \mathrm{A}_{\mathrm{k}} / \mathrm{T}_{\mathrm{i}}=$ efeito do animal $\mathrm{k}$ aninhado ao tratamento $\mathrm{i} ; \mathrm{P}_{\mathrm{j}}=$ efeito do período $\mathrm{j} ; \mathrm{j}=1 ; 2 ; 3 ; \mathrm{e}_{\mathrm{ijk}}=$ erro aleatório associado a cada observação.

Os quadrados médios dos tratamentos foram testados contra os quadrados médios dos animais dentro de tratamento, enquanto quadrados médios de período foram testados contra o quadrado médio do resíduo.

Após avaliação do desempenho dos animais nos diferentes tratamentos, foram avaliados os parâmetros de reposta econômica da suplementação. Foram calculados os valores de custo, utilizando os preços pagos pelos alimentos no período de realização do trabalho. A receita foi calculada com base no ganho médio diário e o preço pago pelo $\mathrm{kg}$ de novilho $(\mathrm{R} \$ 1,86)$ no período de realização do experimento.

A relação receita:custo foi calculada pela equação:

$$
\Sigma \mathrm{R} / \Sigma \mathrm{C}=\Sigma \operatorname{Rn}\left[\left(1 /(1+\mathrm{i})^{\mathrm{n}}\right] / \Sigma \mathrm{Cn}\left[\left(1 /(1+\mathrm{i})^{\mathrm{n}}\right]\right.\right.
$$

em que $\mathrm{R}=$ receita $; \mathrm{C}=$ custo $; \mathrm{i}=$ taxa de desconto $(1 \%) ; \mathrm{n}=$ período de análise.

\section{Resultados e Discussão}

A disponibilidade média de matéria seca total da planta inteira (Tabela 2) nos meses avaliados foi de $2.570 \mathrm{~kg} / \mathrm{ha}$, estando acima de $2.000 \mathrm{~kg} / \mathrm{ha}$, valor este estipulado por Minson (1990) como sendo mínimo para que a disponibilidade de forragem não ocasione diminuição no consumo da pastagem. A disponibilidade média de matéria seca de folhas foi $1.307 \mathrm{~kg} / \mathrm{ha}$.

As ofertas de forragem e de lâminas foliares foram mais elevadas no mês de julho, diminuindo nos demais períodos experimentais. A maior oferta de forragem no início deve-se ao fato de o pasto ter sido vedado e, com o pastejo e o aumento da carga animal, as ofertas de forragem e de lâminas diminuíram.

A proporção de lâminas foliares apresentou um comportamento quadrático $(\mathrm{P}<0,01)$, em função do mês de avaliação $\left(\hat{\mathrm{Y}}=65,16-9,94 \mathrm{x}+1,37 \mathrm{x}^{2}\right.$; $\mathrm{R}^{2}=0,12$ ) (Figura 2). No início do experimento, a proporção de lâminas foliares foi maior, mesmo sendo este o período crítico da seca. Segundo Euclides (2000), isto pode ocorrer porque o pasto foi vedado durante o período de crescimento mais intenso, aumentando a disponibilidade de forragem e, assim, de folhas. A partir do momento que os animais foram colocados na pastagem, a diminuição na proporção de lâminas foliares pode ser decorrente do pastejo 
Tabela 2 - Disponibilidade de matéria seca total (MS) e de lâminas foliares (LF) por hectare, oferta de forragem (OF) e oferta de lâminas foliares (OLF) na pastagem de acordo com os períodos experimentais

Table 2 - Total dry matter (DM) and leaves availability per hectare, forage offer (FO) and leaves offer (LO) in grassland according to the experimental periods

\begin{tabular}{|c|c|c|c|c|}
\hline $\begin{array}{l}\text { Períodos } \\
\text { Periods }\end{array}$ & $\begin{array}{l}\text { MS (kg/ha) } \\
D M(k g / h a)\end{array}$ & $\begin{array}{l}\mathrm{OF}(\mathrm{kg} \text { de MS/100 kg PV) } \\
F O(\mathrm{~kg} D M / 100 \mathrm{~kg} \mathrm{BW})\end{array}$ & $\begin{array}{l}\mathrm{LF}(\mathrm{kg} \text { de MS/ha) } \\
\text { Leaves }(\mathrm{kg} \text { of } D M / \mathrm{ha} \text { ) }\end{array}$ & $\begin{array}{l}\mathrm{OLF}(\mathrm{kg} \text { de MS/100 kg PV) } \\
L O(\mathrm{~kg} D M / 100 \mathrm{~kg} \mathrm{BW})\end{array}$ \\
\hline $\begin{array}{l}\text { Julho/2001 } \\
\text { July/2001 }\end{array}$ & 3119,66 & 28,07 & 1818,76 & 16,40 \\
\hline $\begin{array}{l}\text { Agosto/2001 } \\
\text { August/2001 }\end{array}$ & 2329,27 & 18,57 & 1084,97 & 8,65 \\
\hline $\begin{array}{l}\text { Setembro/2001 } \\
\text { September/2001 }\end{array}$ & 2656,58 & 19,05 & 1324,04 & 9,49 \\
\hline $\begin{array}{l}\text { Outubro/2001 } \\
\text { October/2001 }\end{array}$ & 2045,48 & 13,28 & 991,04 & 6,44 \\
\hline $\begin{array}{l}\text { Novembro/2001 } \\
\text { November/2001 }\end{array}$ & 2700,64 & 15,91 & 1314,40 & 7,75 \\
\hline $\begin{array}{l}\text { Média } \\
\text { Average }\end{array}$ & 2570,33 & 18,99 & 1306,64 & 9,75 \\
\hline
\end{tabular}

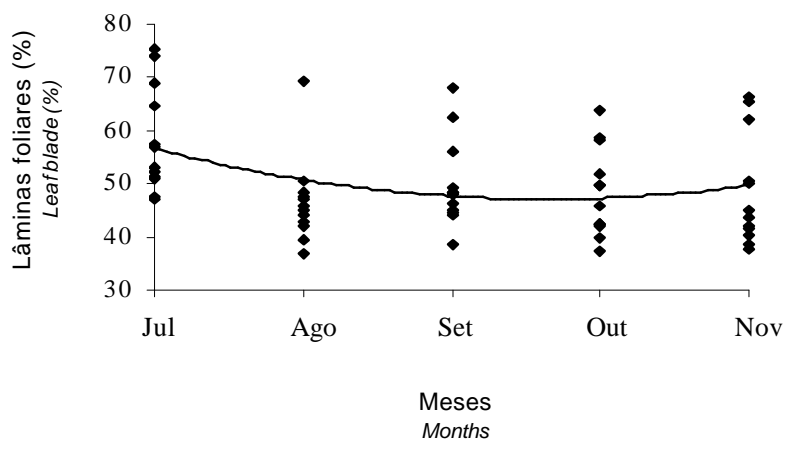

Figura 2 - Proporção de lâminas foliares na pastagem durante os meses de experimento $(n=12)$.

Figure 2 - Leaf proportion of pasture during the experimental months ( $n=12)$.

seletivo dos animais, que tende a consumir maior quantidade de folhas (Carvalho et al., 2001).

No período de transição seca-águas, ou seja, nos meses de outubro e novembro, a proporção de lâminas foliares aumentou. Isso é atribuído ao aumento da precipitação pluviométrica e início da estação de crescimento, aumentando a rebrotação.

Com relação à composição química da forragem disponível, o teor de MS da planta inteira apresentou comportamento cúbico ( $\hat{\mathrm{Y}}=23,32+24,38 \mathrm{x}-8,19 \mathrm{x}^{2}$ $\left.+0,77 x^{3} ; R^{2}=0,62\right)$, em função do mês de avaliação. O maior teor de MS encontrado no início do trabalho pode estar relacionado ao diferimento do pasto e, conseqüentemente, acúmulo de material morto associado à senescência natural da planta forrageira (Euclides, 2000), que pode também ter aumentado no período de junho a agosto pelo déficit hídrico e pela ocorrência de geadas, comuns na região. Nas lâminas foliares e no colmo, o teor de MS não diferiu ( $\mathrm{P}>0,05)$ ao longo dos períodos (Tabela 3).

No que concerne à composição química da forragem, o teor de MO da braquiária em função dos meses de avaliação apresentou comportamento cúbico $\left(\hat{Y}=78,01+14,84 x-5,93 x^{2}+0,66 x^{3} ; R^{2}=0,72\right)$ em função da época de amostragem. À medida que a planta amadurece, a concentração dos componentes potencialmente digestíveis diminui (Euclides, 2000). Os teores de MO da lâmina foliar e do colmo + bainha não diferiram $(\mathrm{P}>0,05)$ entre os meses (Tabela 3 ).

$\mathrm{O}$ teor de $\mathrm{PB}$ da planta inteira apresentou comportamento cúbico, em função dos meses avaliados ( $\hat{Y}=7,88-6,15 x+2,43 x^{2}-0,26 x 3 ; R^{2}=0,73$ ) (Figura 3). Nas lâminas foliares, o teor de PB apresentou aumento linear no avançar dos meses de avaliação ( $\hat{Y}=3,70+0,54 x ; R^{2}=0,36$ ) (Figura 3). Porém, o teor de $\mathrm{PB}$ no colmo + bainha foi semelhante ao longo dos períodos ( $\mathrm{P}>0,05$; Tabela 3$)$.

Paulino et al. (2000) observaram valores inferiores para a PB da Brachiaria decumbens, com média de 2,52\% para todo o período seco. Os teores de PB obtidos por Bomfim et al. (2000) mantiveram-se constantes no período de julho a outubro, sendo sempre inferiores a 3,0\% da MS. 
Os teores de FDN e de FDA da lâmina foliar e colmo + bainha foram semelhantes $(\mathrm{P}>0,05)$ ao longo dos meses (Tabela 3). Por outro lado, o comportamento da curva da FDN da planta inteira foi cúbico $\left(\hat{\mathrm{Y}}=54,76+28,12 \mathrm{x}-10,93 \mathrm{x}^{2}+1,11 \mathrm{x}^{3} ; \mathrm{R}^{2}=0,80\right)$, assim como a curva para a FDA ( $\hat{\mathrm{Y}}=36,95+4,70 \mathrm{x}$ $-1,66 x^{2}+0,16 x^{3} ; R^{2}=0,97$ ) (Figura 4$)$. O comportamento das curvas de FDN e FDA foi oposto ao observado para a PB (Figura 3).

Avaliando o efeito da maturidade sobre as características químicas da Brachiaria decumbens, Paciullo et al. (2000) observaram diminuição dos teores de PB de 7,2\% para 4,6\%, e aumentos nos teores da FDN de 78,9\% para $84,6 \%$ e da FDA de 54,3 para $59,4 \%$, com o amadurecimento da planta.

Observa-se que os valores de PB diminuíram (Figura 3) e os de FDN e FDA aumentaram (Figura 4) nos meses de julho e agosto, pois, à medida que a planta amadurece, a concentração dos componentes digestíveis, como os carboidratos solúveis e as proteínas, diminui e a proporção de fibras aumenta (Euclides, 2000), ocorrendo também redução na relação folha:colmo (Dove, 1998).

A partir de agosto, os valores na planta inteira para PB (Figura 3) aumentaram e para FDN e FDA (Figura 4) diminuíram, sendo mais acentuados nos

Tabela 3 - Teores de matéria seca (MS), matéria orgânica (MO), proteína bruta (PB), extrato etéreo (EE), fibra em detergente neutro (FDN), fibra em detergente ácido (FDA), nutrientes digestíveis totais (NDT) e carboidratos totais (CHOT) da forragem e das frações lâmina foliar e colmo + bainha durante os períodos

Table 3 - Dry matter (DM), organic matter (OM), crude protein (CP), ether extract (EE), neutral detergent fiber (NDF) acid detergent fiber (ADF), total digestive nutrients (TDN) and carbohydrates total (CHOT) of the forage and leaf and stem fraction during periods

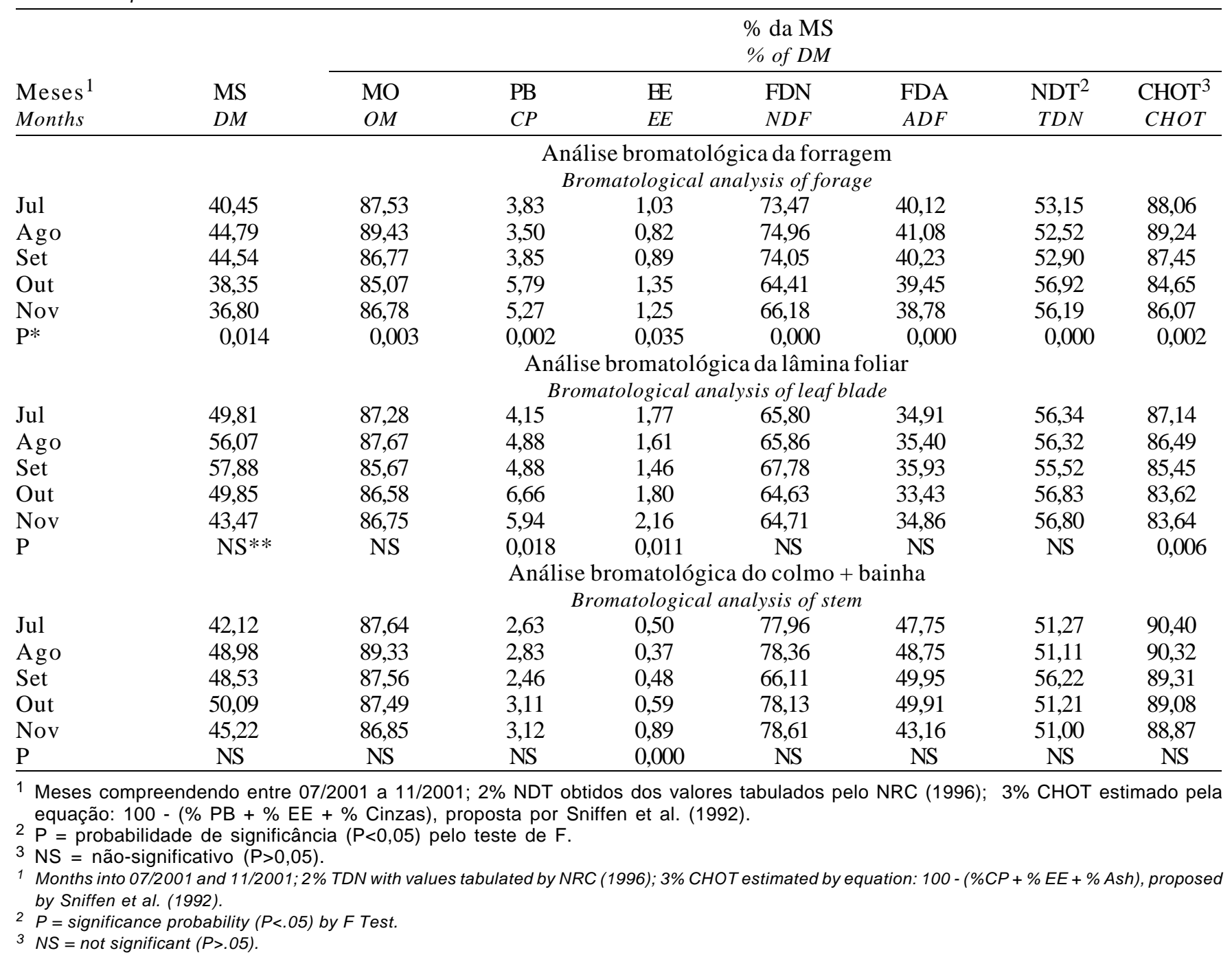

R. Bras. Zootec., v.33, n.6, p.2140-2150, 2004 (Supl. 2) 

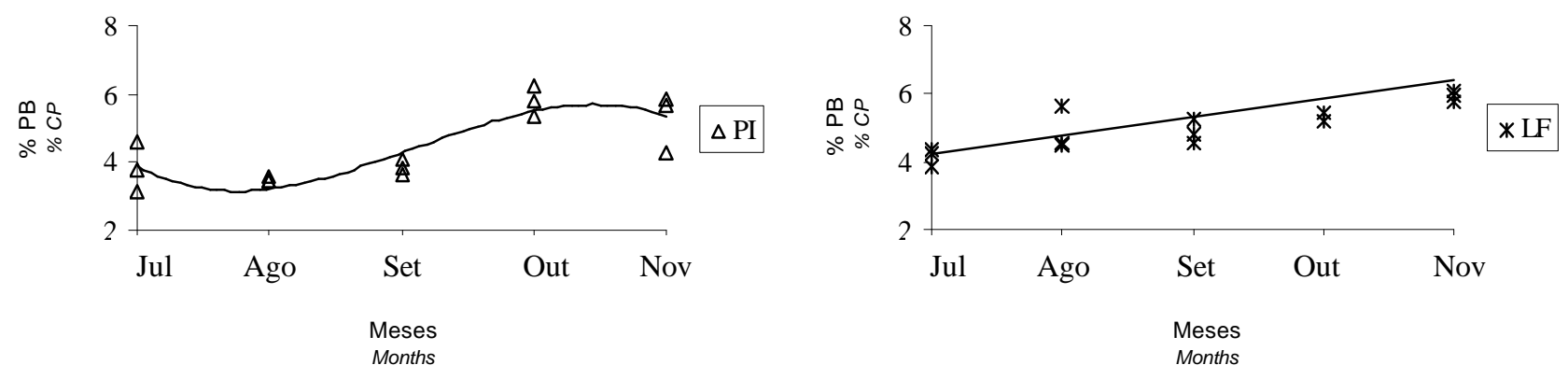

Figura 3 - Teor de proteína bruta (PB) na planta inteira (PI) e das lâminas foliares (LF) da forragem durante os meses de julho a novembro de 2001.

Figure 3 - Crude protein (CP) of forage in whole plant (PI) and leaves (LF) during July and November months of 2001.
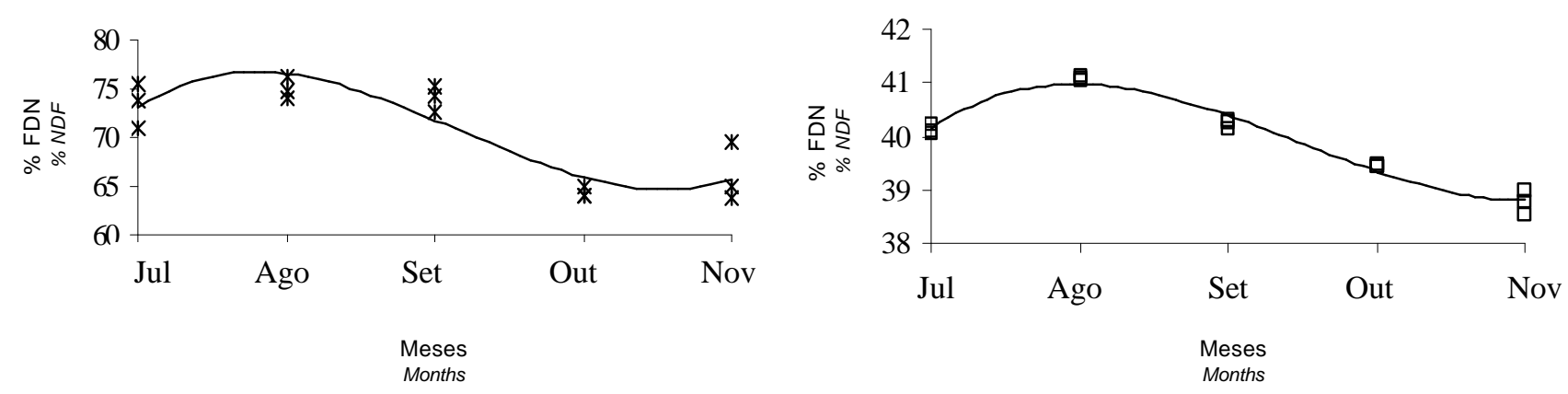

Figura 4 - Teor de fibra em detergente neutro (FDN) e fibra em detergente ácido (FDA) da forragem (planta inteira) durante os meses de julho a novembro de 2001.

Figure 4 - Acid detergent neutral (NDF) and acid detergent fiber (ADF) of the forage (whole plant) during July and November months of 2001.

meses de outubro e novembro, em decorrência do aumento da precipitação pluviométrica (Figura 1) e da rebrotação, no início do período de transição seca-águas.

Com a melhora na proporção de folhas (Figura 2), ou seja, aumento na relação folha:colmo, notam-se, proporcionalmente, acréscimo na concentração de PB e decréscimo na concentração de FDN e FDA observada na planta inteira, pois a concentração de PB na folha é, aproximadamente, o dobro da concentração no colmo, e a folha também apresenta menor concentração em fibras (Nelson \& Moser, 1994), em comparação com o colmo.

Euclides et al. (1996) notaram que a PB na Brachiaria decumbens atingiu teores abaixo do crítico $(<6,0 \%)$ no período seco, mas no período de transição seca-águas, aumentou, chegando a teores acima de $8,0 \%$. O mesmo não foi observado por Gomes Jr. et al. (2002), em que a Brachiaria decumbens apresentou, no mês de outubro, período de transição secaáguas, teor de PB menor e de FDN maior, comparado aos demais meses do ano $(3,53$ e 80,48\%, respectivamente), talvez em razão do baixo índice de precipitação pluviométrica observado durante este período.

Com relação ao NDT, o comportamento da curva foi cúbica $\left(\hat{\mathrm{Y}}=60,95-11,73 \mathrm{x}+4,56 \mathrm{x}^{2}-0,48 \mathrm{x}^{3}\right.$; $\mathrm{r}^{2}=0,80$ ), para a planta inteira (Figura 5). Como o NDT foi calculado a partir dos valores da FDN, quanto maior foi o teor da FDN menor o valor de NDT. Com relação aos valores de NDT das frações lâmina foliar e colmo + bainha, não houve diferenças entre os meses avaliados ( $\mathrm{P}>0,05$; Tabela 3$)$. 


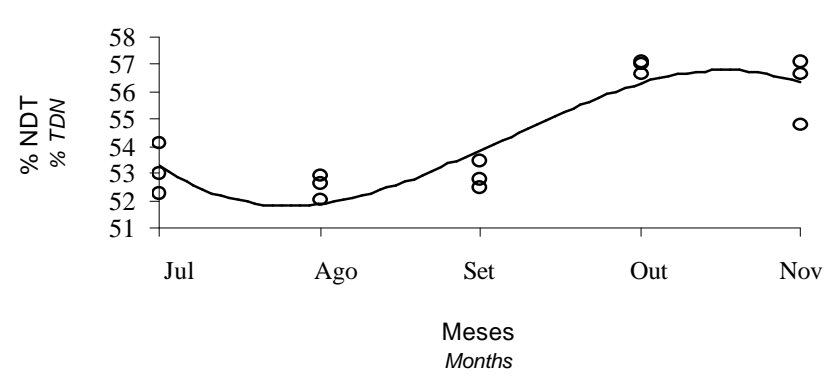

Figura 5 - Teor de nutrientes digestíveis totais (NDT) da forragem (planta inteira) durante os meses de julho a novembro de 2001.

Figure 5 - Total digestive nutrients (TDN) of the forage (whole plant) from July to November of 2001.

A concentração de carboidratos totais apresentou comportamento quadrático, para a planta inteira, em função dos meses de avaliação ( $\hat{Y}=79,36+$ $\left.13,46 x-5,41 x^{2}+0,60 x^{3} ; R^{2}=0,72\right)$. A maior quantidade de CHOT nos primeiros meses deve-se à menor quantidade de PB, EE e MM, assim como ao aumento dos níveis de FDN e FDA. O teor de CHOT na lâmina foliar apresentou comportamento linear ( $\left.\hat{Y}=88,22-0,99 x ; r^{2}=0,45\right)$, no colmo + bainha não houve diferenças entre os períodos ( $\mathrm{P}>0,05$; Tabela 3$)$.

As médias de peso vivo inicial (PVI), peso vivo aos 42 dias (PV-42), 84 dias (PV-84) e 126 dias (PV126), ganho médio diário (GMD) e ganhos por período dos animais suplementados durante o período da seca e transição seca-águas são apresentados na Tabela 4. Entre os suplementos utilizados com diferentes fontes de alimentos energéticos, não houve diferença $(\mathrm{P}>0,05)$ no GMD, o que pode ter ocorrido pelo fato dos suplementos fornecerem teores semelhantes em PB e NDT (Tabela 1).

Os três suplementos proporcionaram ganho de peso semelhante, embora os alimentos que compunham os suplementos apresentassem características diferentes. O milho desintegrado com palha e sabugo, contém alto teor em amido em virtude dos grãos, mas também contém fibra (em média 47\% FDN), proporcionando melhor fermentação ruminal (Paziani, 2000). A farinha de mandioca de varredura é uma fonte rica em energia, tendo como características teores de amido variando de $64 \%$ a $75 \%$ e de FDN de $27 \%$ (Cereda, 1994). A casca do grão de soja apresenta em sua composição, aproximadamente, $12 \%$ de PB e $67 \%$ de FDN (NRC, 1996).

A casca do grão de soja, embora seja um alimento classificado como volumoso seco, proporciona fermentação pelos microrganismos ruminais, tornando assim, uma fonte disponível de energia, e a digestibilidade total é acima de $70 \%$ para todos os nutrientes (Faulkner et al., 1994), melhorando a utilização de forragens de baixa qualidade (Martin \& Hibberd,1990; Kohlmeier, 1996; Kung \& Lin, 1997).

$\mathrm{O}$ aumento de peso observado do início do experimento até o segundo período (84 dias) pode ser decorrente de ganho compensatório, pois esses animais antes de iniciar o experimento estavam submetidos à condição de restrição alimentar e, no final desse período, o aumento do ganho de peso decorreu

Tabela 4 - Médias de peso vivo inicial (PVI), peso vivo aos 42 dias (PV-42), 84 dias (PV-82) e 126 dias (PV-126) e ganho médio diário (GMD) em função dos suplementos e nos períodos experimentais

Table 4 - Means of initial body weight (IBW), body weight at 42 days (BW-42), at 84 days (BW-84) and at 126 days (BW-126) and daily average gain (ADG) for different supplements and experimental periods

\begin{tabular}{lccc}
\hline & \multicolumn{3}{c}{$\begin{array}{c}\text { Suplementos } \\
\text { Supplements }\end{array}$} \\
\cline { 2 - 4 } & SMDPS & SFMV & SCGS \\
& SCCH & SCM & SSH \\
\hline PVI & 197,43 & 196,43 & 201,93 \\
BWI & & & \\
PV-42 & 228,63 & 231,16 & 235,53 \\
BW-42 & & & \\
PV-84 & 270,76 & 276,35 & 280,21 \\
BW-84 & & & \\
PV-126 & 298,86 & 304,54 & 308,83 \\
BW-126 & & & \\
GMD (kg/animal/dia)* & 0,805 & 0,858 & 0,846 \\
ADG (kg/animal/day) & & & \\
Períodos ${ }^{2}$ & & & \\
Periods ${ }^{2}$ & & & \\
1 & $0,743 \mathrm{~b}$ & $0,827 \mathrm{~b}$ & $0,800 \mathrm{~b}$ \\
2 & $1,003 \mathrm{a}$ & $1,076 \mathrm{a}$ & $1,064 \mathrm{a}$ \\
3 & $0,668 \mathrm{~b}$ & $0,670 \mathrm{~b}$ & $0,674 \mathrm{~b}$ \\
CV (\%) & 17,11 & 16,02 & 16,23 \\
\hline
\end{tabular}

1 Suplementos: SMDPS: milho desintegrado com palha e sabugo + farelo de algodão; SFMV: farinha de mandioca de varredura + farelo de algodão; SCGS: casca do grão de soja + farelo de algodão.

2 Períodos: 1 - 20/07/2001 a 31/08/2001; 2 - 31/08/2001 a 12/10/ 2001; 3 - 12/10/2001 a 23/11/2001.

* $\mathrm{CV}=16,42 \%$.

Médias seguidas com letras diferentes na mesma coluna diferem entre si pelo teste Tukey $(P<0,05)$.

1 Supplements: SCCH: corn and cobs with husks + cottonseed meal; SCM: cassava meal + cottonseed meal; SSH: soybean hulls + cottonseed meal.

2 Periods: 1 - 07/20/2001 to 08/31/2001; 2 - 08/31/2001 to 10/12/2001; 3 - 10/12/2001 to 11/23/2001.

Means with different letter in the same column are different by Tukey test $(P<.05)$.

${ }^{*} \mathrm{CV}=16.42 \%$.

R. Bras. Zootec., v.33, n.6, p.2140-2150, 2004 (Supl. 2) 
de maior uso de energia metabolizável para ganho de energia corporal. O período de compensação pode ser de 60 a 90 dias, mas a duração desses efeitos é muito variável (NRC, 1996).

No segundo período (84 dias), o GMD foi superior $(\mathrm{P}<0,05)$ ao observado no primeiro período, sendo este acima de 1,0 kg/animal/dia. A diminuição no GMD observado no terceiro período (126 dias) pode ser decorrente da categoria de peso dos animais, pois, ao entrar neste período, os animais estavam com média de $275 \mathrm{~kg}$ de PV, sendo as exigências para manutenção e produção maiores. Outro fator que pode ter acarretado essa diminuição no peso dos animais foi a redução da oferta de forragem, principalmente a diminuição da oferta de lâminas foliares, que passou de $16,40 \mathrm{~kg}$ de MS/100 kg PV, no início das avaliações, para 7,75 kg de MS/100 kg, no último período.

A suplementação protéica e energética no período da seca pode melhorar a eficiência e utilização de forragens maduras pelo fornecimento de energia adicional para os microrganismos (Heldt et al., 1998). Isso foi observado por Manella et al. (2000), que, ao utilizarem apenas a suplementação protéica no período da seca, o GMD foi de $0,534 \mathrm{~kg} /$ animal. Este ganho poderia ter sido maior, pois a energia foi of fator limitante.

Há grande variação nos resultados de ganho de peso animal entre os trabalhos consultados, em decorrência de fatores como as diferenças entre animais (raça e peso vivo), pastagens (qualidade e disponibilidade), suplementos (fontes e níveis de suplementação) e o período avaliado (seca e águas).
Tabela 5 - Valores de aquisição dos componentes dos suplementos utilizados em reais $(R \$)$

Table 5 - Purchase values of supplement components

\begin{tabular}{lc}
\hline $\begin{array}{l}\text { Alimentos } \\
\text { Feedstuffs }\end{array}$ & $\begin{array}{c}\text { Valor }(\mathrm{R} \$ / \mathrm{t})^{1} \\
\text { Values }(R \$ / t)\end{array}$ \\
\hline $\begin{array}{l}\text { Milho desintegrado com palha e sabugo } \\
\text { Corn and cobs with husks }\end{array}$ & 147,00 \\
$\begin{array}{l}\text { Farinha de mandioca de varredura } \\
\text { Cassava meal }\end{array}$ & 100,00 \\
$\begin{array}{l}\text { Casca do grão de soja } \\
\text { Soybean hulls }\end{array}$ & 130,00 \\
Farelo de algodão & 220,00 \\
Cottonseed meal & \\
\hline
\end{tabular}

1 Os alimentos foram cotados em 03/2001.

1 The feeds were quoted in 03/2001.

Constam na Tabela 5 os valores pagos em fevereiro de 2001 para cada alimento componente dos suplementos.

Os resultados dos cálculos de retorno econômico da suplementação encontram-se na Tabela 6. O suplemento contendo farinha de mandioca de varredura (SFMV) foi o que apresentou menor custo (R \$/animal/dia), comparado àquele com casca de grão de soja (SCGS), e este, por sua vez, apresentou menor custo que o suplemento contendo milho desintegrado com palha e sabugo (SMDPS). Na ordem inversa aos custos, apresenta-se o ganho médio diário (GMD), ou seja, os suplementos que custaram menos foram os que proporcionaram maior GMD, sendo, portanto, a melhor resposta econômica correspondente ao melhor desempenho biológico.

Tabela 6 - Descrição do ganho médio diário (GMD kg/animal/dia), custos ( $\mathrm{R} \$ / \mathrm{animal} / \mathrm{dia})$, custos/kg ( $\mathrm{R} \$ / \mathrm{kg}$ de ganho/ dia), receita $(R \$ /$ dia) e relação receita: custo $(R: C-R \$)$ para cada animal suplementado

Table 6 - Description of average dairy gain (ADG, kg/animal/day), costs(R\$/animal/day), costs/kg (R\$/kg of gain), income (R\$) and income cost ratio (I:C) to each animal supplemented

\begin{tabular}{|c|c|c|c|c|c|}
\hline $\begin{array}{l}\text { Suplementos } \\
\text { Supplements }^{1}\end{array}$ & $\begin{array}{l}\operatorname{GMD}(\mathrm{kg} / \mathrm{an} / \mathrm{d}) \\
A D G(\mathrm{~kg} / \mathrm{an} / \mathrm{d})\end{array}$ & $\begin{array}{c}\text { Custos }(\mathrm{R} \$ / \mathrm{an} / \mathrm{dia}) \\
\text { Costs }(R \$ / \text { an } / \text { day })\end{array}$ & $\begin{array}{c}\text { Custos } / \mathrm{kg}(\mathrm{R} \$ / \mathrm{kg} \text { de ganho/dia }) \\
\text { Costs }(R \$ / \mathrm{kg} \text { of gain/day })\end{array}$ & $\begin{array}{l}\operatorname{Receita}^{2}(\mathrm{R} \$) \\
\text { Income }(R \$)\end{array}$ & $\begin{aligned} \mathrm{R}: \mathrm{C}^{3} \\
\mathrm{I}: C\end{aligned}$ \\
\hline $\begin{array}{l}\text { SMDPS } \\
\text { SCCH }\end{array}$ & 0,805 & 0,622 & 0,808 & 1,052 & 1,30 \\
\hline $\begin{array}{l}\text { SFMV } \\
S C M\end{array}$ & 0,858 & 0,559 & 0,666 & 1,194 & 1,79 \\
\hline $\begin{array}{l}\text { SCGS } \\
\text { SSH }\end{array}$ & 0,846 & 0,566 & 0,676 & 1,184 & 1,75 \\
\hline
\end{tabular}

${ }^{1}$ Suplementos: SMDPS: milho desintegrado com palha e sabugo + farelo de algodão; SFMV: farinha de mandioca de varredura + farelo de algodão; SCGS: casca do grão de soja + farelo de algodão.

${ }^{2}$ Receita $=$ GMD $\times \mathrm{R} \$ 1,86$ (preço pago pelo $\mathrm{kg}$ de novilho no período).

${ }^{3} \mathrm{R}: \mathrm{C}=$ receita/custo.

${ }^{1}$ Supplements: SCCH: corn and cobs with husks + cottonseed meal; SCM: cassava meal + cottonseed meal; SSH: soybean hulls + cottonseed meal.

2 Income $=A D G \times R \$ 1,86$.

${ }^{3} \mathrm{I}: \mathrm{C}=$ income/cost. 
O custo para produzir $1 \mathrm{~kg}$ de ganho de peso diário (custo/kg) foi, portanto, menor para SFMV que para SCGS e SMDPS, obtendo-se valores de relação receita:custo de 1,$79 ; 1,75$ e 1,30 , respectivamente, para SFMV, SCGS e SMDPS. De maneira geral, os investimentos são viáveis toda vez que a relação $\mathrm{R}: \mathrm{C}$ está acima de 1 . Conforme pode ser observado na Tabela 6, todos os suplementos apresentaram R:C acima de 1 , sendo os três suplementos viáveis, nas condições deste trabalho.

Pilau et al. (2003), avaliando sistemas de produção para novilhas de corte, observaram que os animais exclusivamente em pastejo sob disponibilidade de forragem baixa apresentam ganho de peso vivo suficiente apenas para cobrir os custos de produção. Independentemente da oferta de forragem, os sistemas com suplementação energética proporcionaram ganho de $\mathrm{PV} / \mathrm{ha}$ superior aos sistemas sem suplementação.

A grande vantagem de investir na suplementação em relação ao uso exclusivo da pastagem está no baixo risco ligado ao fornecimento do suplemento, pois a quantidade oferecida não depende de condições climáticas. Outra vantagem da suplementação é a aceleração no ganho de peso dos animais, antecipando a liberação da área para outras categorias (Euclides et al., 1998).

\section{Conclusões}

Os suplementos constituídos com diferentes fontes energéticas proporcionaram ganhos semelhantes para novilhos Nelore em pastagens de Brachiaria decumbens, nos períodos da seca e de transição seca-águas.

Os três suplementos foram viáveis economicamente, mas o constituído de farinha de mandioca de varredura proporcionou melhor relação receita: custo.

\section{Literatura Citada}

ANDERSON, S.J.; MERRILL, J.K.; KLOPFENSTEIN, T.J. Soybean hulls as an energy supplement for the grazing ruminant. Journal of Animal Science, v.66, n.11, p.2965-2976, 1988. ANDRADE, P. Alimentação de bovinos em épocas críticas. In: PEIXOTO, A.M.; MOURA, J.C.; FARIA, P.F. (Eds.) Nutrição de bovinos. Conceitos básicos e aplicados. 2.ed. Piracicaba: Fundação de Estudos Agrários Luiz de Queiroz, 1995. p.239-250.

BOMFIM, M.A.D.; REZENDE, C.A.P.; PAIVA, P.C.A. et al. Níveis de concentrado na terminação de novilhos Holandês $x$ Zebu suplementados a pasto na estação seca. In: REUNIÃO
ANUAL DA SOCIEDADE BRASILEIRA DE ZOOTECNIA, 37., 2000, Viçosa, MG. Anais...Viçosa, MG: Sociedade Brasileira de Zootecnia/Gmosis, [2000] 834 par. CD-ROM. Nutrição de Ruminantes.

CAPELLE, E.R.; VALADARES FILHO, S.C.; COELHO da SILVA, J.F. et al. Estimativas do valor energético a partir de características químicas e bromatológicas dos alimentos. Revista Brasileira de Zootecnia, n.30, v.6, p.1837-1856, 2001.

CARDOSO, A.G.; VITTO, G.; NOGUEIRA, M.P. A importância da suplementação protéica para os animais. Revista Pecuária de Corte, v.8, n.80, p.70-74, 1998.

CARVALHO, P.C.F.; RIBEIRO FILHO, H.M.N.; POLI, C.H.E.C. et al. Importância da estrutura da pastagem na ingestão e seleção de dietas pelo animal em pastejo. In: REUNIÃO ANUAL DA SOCIEDADE BRASILEIRA DE ZOOTECNIA, 38., 2001, Piracicaba. Anais...Piracicaba: Sociedade Brasileira de Zootecnia, 2001. p.853-871.

CATON, J.S.; DHUYVETTER, D.V. Influence of energy supplementation on grazing ruminantes: requeriments and responses. Journal of Animal Science, v.75, n.2, p.533-542, 1997.

CEREDA, M.P. Resíduos da industrialização da mandioca no Brasil. São Paulo: Paulicéia, 1994. 174p.

DOVE, $\mathrm{H}$. The ruminant, the rumen and the pasture resource: nutrient interactions in the grazing animal. In: HODGSON, J.; ILLIUS, A.W. (Eds.) The ecology and management if grazing systems. 2.ed. London: CAB International, 1998. 466p.

EMBRAPA. Suplementação mineral racional. 15/09/1995 < http://www .sbz.org.br/ atualidades/suplementacaomineral.htm $<29 / 04 / 2000$.

EUCLIDES FILHO, K.; EUCLIDES, V.P.B.; FIGUEIREDO, G.R. Efeito da suplementação com concentrado sobre a idade de abate e características de carcaça do animal Nelore. Revista Brasileira de Zootecnia, v.26, n.6, p.1096-1102, 1997.

EUCLIDES, V.P.B; MACEDO, M.C.M; VIEIRA, A. et al. Valores nutritivos de cinco gramíneas sob pastejo. In: REUNIÃO ANUAL DA SOCIEDADE BRASILEIRA DE ZOOTECNIA, 32., 1996, Fortaleza. Anais...Fortaleza: Sociedade Brasileira de Zootecnia, 1996, p.90-92.

EUCLIDES, V.P.B.; EUCLIDES FILHO; K.E., ARRUDA, Z.J. et al. Desempenho de novilhos em pastagens de Brachiaria decumbens submetidos a diferentes regimes alimentares. Revista Brasileira de Zootecnia, v.27, n.2, p.246-254, 1998.

EUCLIDES, V.P.B. Intensificação da produção de carne bovina em pastagem. Curso de suplementação em pasto e confinamento de bovinos. 2000. capturado em: <http://www.embrapa.com.br/ gadodecorte $<13 / 02 / 2002$

FAULKNER, D.B.; HUMMEL, D.F.; BUSKIRK, L.L. et al. Performance and nutrient metabolism by nursing calves supplemented with limited or unlimited corn or soyhulls. Journal of Animal Science, n.72, v.5, p.420-450, 1994.

GARDNER, A.L. 1986. Técnicas de pesquisa em pastagens e aplicabilidade de resultados em sistemas de produção. Brasília: IICA, EMBRAPA - CNPGL. 197p.

GOMES JR., P.; PAULINO, M.F.; DETMANN, E. et al. Composição químico-bromatológica da Brachiaria decumbens sob pastejo: proteínas e carboidratos. In: REUNIÃO ANUAL DA SOCIEDADE BRASILEIRA DE ZOOTECNIA, 39., 2002, Recife. Anais...Recife: Sociedade Brasileira de Zootecnia/ Gmosis, [2002] 547 par. CD-ROM. Forragicultura.

HELDT, J.S.; PRUITT, R.J.; BIRKELO, C.P. et al. Evaluation of wheat middling as a supplement for beef cows grazing native winter range with differing forage availabilities. Journal of Animal Science, v.76, n.2, p.378-387, 1998. 
HOLDERBAUN, J.F.; SOLLENBERG, K.H. Canopy structure and nutritive value of limpograss pastures during midsummer to early autumn. Agronomy Journal, v.84, n.1, p.11-16, 1992.

KOHLMEIER, R.H. The use of soybean hulls for ruminants and other species. 1996. capturado em: <. http:// www.asasea.com/technical/an.2rhk96.html $<10 / 11 / 2000$.

KUNG, L.J.; LIN, C. Soyhulls in beef and dairy cattle nutrition. 1997. capturado em: < http://www.asasea.com/technical/ an16.1997.html $<10 / 11 / 2000$.

MANELLA, M.Q.; LOURENÇO, A.J.; LEME, P.R. Bovinos Nelore em pastos de Brachiaria brizantha com suplementação protéica ou com acesso a banco de proteína de Leucena leucocephala. In: REUNIÃO ANUAL DA SOCIEDADE BRASILEIRA DE ZOOTECNIA, 37., 2000, Viçosa. Anais...Viçosa: Sociedade Brasileira de Zootecnia/Gmosis, [2000] 693 par. CD-ROM. Nutrição de Ruminantes.

MARTIN, S.K.; HIBBERD, C.A. Intake and digestibility of lowquality native grass hay beef cows supplemented with graded levels of soybean hulls. Journal of Animal Science, v.68, n.12, p.4319-4325, 1990.

MINSON, D.J. Forage in ruminant nutrition. San Diego: Academic Press, 1990. 483p.

NATIONAL RESEARCH COUNCIL - NRC. Nutrient requirements of beef cattle. 7.ed. Washington, D.C.: 1996. 242p.

NELSON, C.J.; MOSER, I.E. Plant factors affecting forage quality. In: FAHEY, G.C.J. (Ed) Forage quality, evaluation and utilization. Madison: Wicosin, 1994. p.115-154.

PACIULLO, D.S.C.; GOMIDE, J.A.; QUEIROZ, D.S. et al. Composição química e digestibilidade de lâminas foliares e colmos em diferentes idades e níveis de inserção no perfilho de gramíneas forrageiras. In: REUNIÃO ANUAL DA SOCIEDADE BRASILEIRA DE ZOOTECNIA, 37., 2000, Viçosa. Anais...Viçosa: Sociedade Brasileira de Zootecnia/ Gmosis, [2000] 329 par. CD-ROM. Forragicultura

PAULINO, M.F.; DETMANN, E.; VALADARES FILHO, S.C. Soja grão e caroço de algodão em suplementos múltiplos para terminação de bovinos mestiços em pastejo. In: REUNIÃO ANUAL DA SOCIEDADE BRASILEIRA DE ZOOTECNIA, 37., 2000, Viçosa, MG. Anais...Viçosa, MG: Sociedade Brasileira de Zootecnia/Gmosis, [2000] 1075 par. CD-ROM. Nutrição de ruminantes.
PAZIANI, S.F. Digestibilidade e degradabilidade de rações à base de milho desintegrado com palha e sabugo em diferentes granulometrias. Jaboticabal: Universidade Estadual de São Paulo, 2000. 67p. Dissertação (Mestrado em Zootecnia) Universidade Estadual de São Paulo, 2000.

PERUCHENA, C.A. Suplementación de bovinos para carne sobre pasturas tropicales, aspectos nutricionales, productivos y economicos. In: REUNIÃO ANUAL DA SOCIEDADE BRASILEIRA DE ZOOTECNIA, 36., 1999, Porto Alegre. Anais... São Paulo: Sociedade Brasileira de Zootecnia/Gmosis, [1999]. CD-ROM. Nutrição de Ruminantes.

PILAU, A.; ROCHA, M.G.; SANTOS, D.T. Análise econômica de sistemas de produção para recria de bezerras de corte. Revista Brasileira de Zootecnia, v.32, n.4, p.966-976, 2003.

POPPI, D.P.; McLENNAN, S.R. Protein and energy utilization by ruminant at pasture. Journal of Animal Science, v.73, n.1, p.278-290, 1995.

SILVA, D.J. Análise de alimentos: métodos químicos e biológicos. Viçosa, MG: Universidade Federal de Viçosa, 1990. 165p.

SNIFFEN, C.J.; O'CONNOR, J.D.; Van SOEST, P.J. et al. A net carbohydrate and protein system for evaluating cattle diets: II. Carbohydrate and protein availability. Journal of Animal Science, v.70, n.10, p.3562-3577, 1992.

UNIVERSIDADE FEDERAL DE VIÇOSA - UFV. Central de Processamento de Dados - UFV - CPD. SAEG -Sistema para Análise Estatística e Genética. Viçosa, MG, 1982. 59p.

VAZANT, E.S.; COCHRAN, R.C. Performance and forage utilization by beef cattle receiving increasing amounts of alfafa hay as a supplement to low quality, tallgrassprairie forage. Journal of Animal Science, v.72, n.4, p.1059-1067, 1994.

WILM, H.G.; COSTELLO, O.F.; KLIPPLE, G.E. Estimating forage yield by the double sampling method. Journal of American Society Agronomy, v.36, n.1, p.194-203, 1944. 